
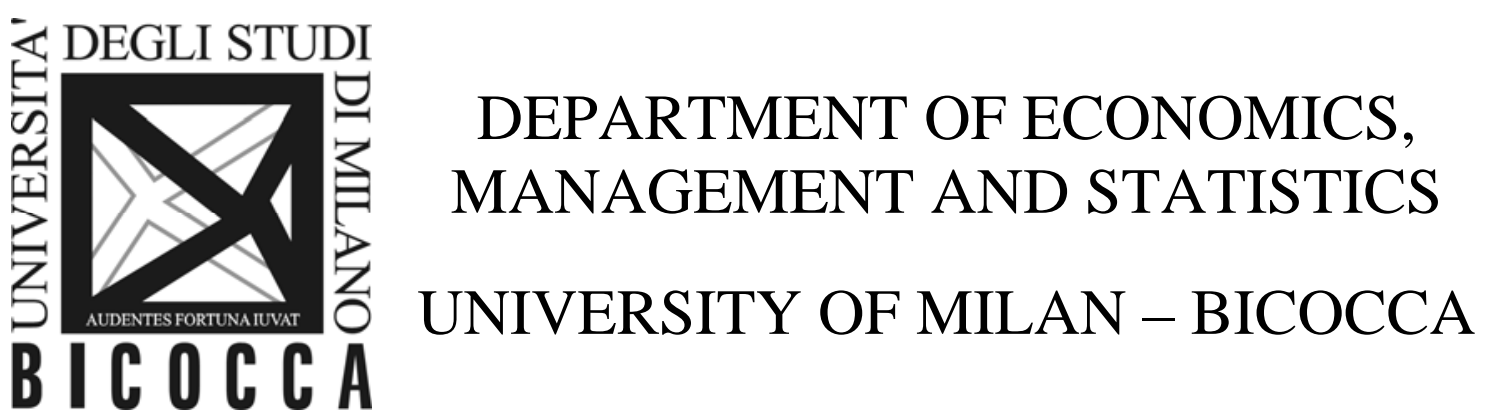

DEMS WORKING PAPER SERIES

\title{
Information transmission and ownership consolidation in aid programs
}

\author{
Axel Dreher, Silvia Marchesi
}

No. 255 - October 2013

Dipartimento di Economia, Metodi Quantitativi e Strategie di Impresa Università degli Studi di Milano - Bicocca http://dems.unimib.it/ 


\title{
Information transmission and ownership consolidation in aid programs
}

\author{
Axel Dreher \\ Heidelberg University \\ Silvia Marchesi \\ Università di Milano Bicocca and Centro Studi Luca d'Agliano
}

October 11, 2013

\begin{abstract}
This paper explores the role of information transmission in explaining donors' choice between project aid and budget support. Budget support increases the involvement of recipient governments in the decision-making process and can thus be an example of a "delegation-scheme." Conversely, project aid represents a more "centralized" type of aid. According to the theory, when countries' local knowledge is more important than donors' information, recipient countries' discretion in the choice of policies should be increased (delegation). Conversely, there should be less freedom in designing policies when donors' information is more relevant (centralization). The empirical analysis confirms that the importance of donors' private information influences the amount of project aid, while recipients' local knowledge is positively correlated with the amount of budget support.
\end{abstract}

Keywords: Delegation, communication, ownership, foreign aid

JEL Classifications: C23, D82, F33, O1

Acknowledgements: We thank Jamie Parsons for proof-reading. E-mail addresses: mail@axeldreher.de, silvia.marchesi@unimib.it 


\section{Introduction}

Over the last twenty years geopolitical and global economic changes have modified the way official foreign aid is provided. The so-called "new rhetoric on aid" has recognized the importance of a greater selectivity among donors and that of encouraging greater ownership of development programs in recipient countries (e.g., see the Paris Declaration on Aid Effectiveness 2005). In particular, "ownership" has been seen as crucial for the successful implementation of conditional reform programs and basing reform designs on context-specific knowledge could be one way to stimulate recipient countries' ownership. ${ }^{1}$

In this paper we focus on how to improve the design of aid programs considering the role that both donors and recipients should play in the design of these programs. Modeling the link between donor-recipient communication and program design is the main contribution of this paper. ${ }^{2}$

Countries' local knowledge often consists of unverifiable information (or verifiable only at a high cost) and so the quality of the reports crucially depends on the conflict of interest between the sender (the recipient) and the receiver (the donor). The donor, as well as the recipient country, also owns some private information that is relevant to the implementation of effective polices. In this setting, mutual communication is important as the donor possesses skills and information which are useful in processing the country's local information, thus aiding the design of the "optimal" policy package. ${ }^{3}$ Thus, the analytical setting is one of two-sided incomplete information where agency problems have the indirect negative effect of preventing full communication between the sender and the receiver.

As in Marchesi et al. (2011) we model the transmission of information between the donor and the recipient country as a cheap talk game (Crawford and Sobel 1982). More specifically,

\footnotetext{
${ }^{1}$ In the words of Koeberle (2004: 15) ownership is the "commitment to aid-supported reforms by country authorities and a majority of domestic stakeholders." According to Khan and Sharma (2001: 13) ownership "refers to a situation in which the policy content of the program is similar to what the country itself would have chosen in the absence of IMF involvement." The IMF (2001: 6) defines it as "a willing assumption of responsibility for an agreed program of policies, by officials in a borrowing country who have the responsibility to formulate and carry out those policies, based on an understanding that the program is achievable and is in the country's own interest."

${ }^{2}$ The mechanisms and circumstances under which such information should be transferred by recipient countries to donors (or lenders) have rarely been investigated. An exception is Marchesi et al. (2011) who analyzed the specific case of communication between the IMF and a borrowing country.

${ }^{3}$ More specifically, aid in the form of budget support would be linked to agreed policy packages (in particular those implementing policy recommendations made by the IMF and the World Bank) which allows us to assume that donors also possess some informational advantage. In the case of project aid donors may also have a sort of "technological advantage" implying some superior information about the design of projects.
} 
we assume information to be "soft" and the transmission of information to be costless. We compare two types of incentive schemes (delegation vs. centralization) relative to the quality of the transmitted information. We define "centralization" as a framework in which control rights over policies are assigned to the donor. On the contrary, we define "delegation" as a framework in which the recipient country is left with considerable freedom to devise its own policy actions, ultimately being judged by the outcomes.

We consider a situation in which the recipient is biased in favor of the "status quo," whereas the donor is biased in favor of more (or deeper) policy reforms relative to the recipient. In both delegation and centralization, such misalignment of interests prevents full communication. Therefore, the optimal allocation of control rights over policies from the donor's perspective will depend on the relative importance of the two parties' information, as well as the size of the agency bias, which simultaneously affects the amount of the information transmitted and the implemented reforms.

In line with Marchesi et al. (2011), the main theoretical findings are then as follows. For a given agency bias, when recipient's local knowledge is more important than the donor's information their discretion in the choice of policies (delegation) should be increased. Conversely, there should be less freedom in designing policies (centralization) when the donor's information is more relevant. As far as the effect of the agency bias is concerned, there are two opposite effects. Intuition would suggest that an increase in the conflict of interests between the donor and the recipient would make the former more inclined towards "centralization." The agency bias, however, also affects the quality of communication and, since an increase in the bias reduces the amount of information transferred to the donor by the recipient under centralization, the donor's incentive to delegate may increase, particularly when local knowledge is crucial for designing the donor's preferred policies.

An immediate empirical implication of the model would be to investigate the way in which aid is disbursed in relation to information transmission problems. We focus on two distinct ways of delivering aid, budget support and project aid. Budget support increases the involvement of the recipient governments in the decision-making process and can thus be an example of a "delegation-scheme." 4 Conversely, project aid represents a more "centralized" type of aid. We therefore investigate the importance of donor/recipient private information

\footnotetext{
${ }^{4}$ Koeberle and Stavreski (2006), among others, also argue that by increasing the use of general budget support, donors would also increase the involvement of the recipients as this type of aid is financial support to the public budgets of the recipients. However, as argued by Dietrich (2010), for the very same reason, one would expect budget support to be targeted to recipients with a relatively high quality of governance and sound macroeconomic policies.
} 
as determinants of project and budget aid. Controlling for countries' characteristics and their economic performance (and for the political motivations of aid) we find that the importance of donors' private information does influence the amount of project aid they give, while recipients' local knowledge is positively correlated with the amount of budget support.

The paper is organized as follows. Section 2 briefly describes the related literature. A sketch of the model is developed in Section 3. Section 4 describes the empirical model, while we discuss the results in Section 5. The final Section 6 concludes.

\section{$2 \quad$ Related literature}

This paper relates to two strands of literature. The first is the literature on aid allocation and selectivity. This literature tries to disentangle the various motives of donors when giving aid, usually referring to commercial, geo-strategic, developmental, and "good policy"-related motives (see, e.g., Alesina and Dollar 2000, Kuziemko and Werker 2006, Dreher et al. 2009a, 2009b). Most directly related to the question we focus on in this paper are those few studies that address the choice between project and budget aid both theoretically and empirically (see for, example, Chauvet et al. 2013, Cordella and dell'Ariccia 2007, Hefeker 2006, Koeberle and Stavreski 2006, Outtara and Strobl 2010). Cordella and dell'Ariccia's (2007) model (analytically) relates the choice between project aid and conditional budget support to the different preferences between donors and recipients. Specifically, they show that budget support is preferable to project aid when the donor's preferences are close to those of the recipient and the amount of aid is small relative to the recipients' own resources. ${ }^{5}$ Similarly, Chauvet et al. (2013) have also related the existence of a conflict of interest between donors and recipients to the choice of (donors' supervision of) project aid. Applying principal-agent theory to the performance of aid projects they show that in a wide range of circumstances the principal (the donor) should put greater effort into supervision when the difference between their preferences and the agent's (the recipient) is greater. They test this prediction using data on World Bank project performance and, consistent with their theory, find that donor supervision of projects is significantly more effective in improving project performance when interests are widely divergent. ${ }^{6}$

Like we do in this paper, Cordella and dell'Ariccia (2007) and Chauvet et al. (2013) use a principal-agent framework and relate the conflict of interest between donors and recipients

\footnotetext{
${ }^{5}$ This result depends on aid fungibility: in aid-dependent countries, in which project aid is larger relative to domestic resources, the probability that the recipient government manages to reallocate its own resources becomes low and so project aid becomes a better instrument than budget support (i.e., fungibility is low).

${ }^{6}$ Nevertheless, donors do not put more effort into the supervision of projects in such cases.
} 
to the choice of whether to give aid as budget support or project aid. None of them, however, has considered the importance of communication between the donor and the recipient for the design of policies, nor have they related the choice between these different aid schemes to the importance of fostering communication between the two.

There are however some empirical studies trying to estimate the relationship between disaggregated aid flows and economic growth, such as Clemens et al. (2012), Rajan and Subramanian (2008) and Outtara and Strobl (2008). The results differ substantially between these studies, suggesting they lack robustness. While Clemens et al. find a significant positive effect of short-impact aid (such as budget and balance of payments support), the results in Outtara and Strobl show a significantly negative effect of financial program aid (budget support) and a significant and positive effect of project aid. Rajan and Subramanian do not find evidence of any significant effects of aid on growth, regardless of its type. Also closely related, Nordtveit (2012) investigates the choice between project and budget aid, testing whether donors are more selective in the choice of this type of aid which gives the recipients more freedom. Nordtveit finds that donors are not selective in their allocation of budget support since they tend to favor former colonies and follow other donors when choosing recipients of budget support (herd behavior).

The second strand of literature to which this paper relates is primarily concerned with the role of donors (or lenders) in designing development reforms and thus to the importance of enhancing recipients' "ownership." 7 The principle that ownership is crucial for the (successful) implementation of reforms is now well established. As emphasized by various studies including Besley and Persson (2011), Dixit (2009), Easterly (2006, 2008), Rajan (2008), Mallaby (2004), and Marchesi et al. (2011), institutions and policies are context-specific and donors and lenders do well to base their policies on a good knowledge of the recipient country's characteristics, which in turn implies greater ownership of policies in recipient countries. Nevertheless, the mechanisms and circumstances under which such knowledge should be transferred by donor countries to the recipients have rarely been investigated. ${ }^{8}$

Aid ownership has also (theoretically) been addressed by Hagen (2010). In his model, increasing delegation in aid flows would be associated to giving money either with "no-conditions-

\footnotetext{
${ }^{7}$ More generally the relationship between decentralization and development has been analyzed, among others, by Bardhan (2002) and, more recently, Lessmann and Markwardt (2010).

${ }^{8}$ An exception is Marchesi et al. (2011), who, building on the cheap talk literature (Crawford and Sobel 1982, Dessein 2002, Harris and Raviv 2005, 2008), have identified and tested the conditions under which it is optimal for the International Monetary Fund to delegate control to a recipient country in order to maximize the quality of the reform program. More recently, and in a different context, Dreher et al. (2013a) explores the role of information transmission in explaining the optimal degree of decentralization across countries.
} 
attached" or with conditions being limited to achieving certain outcomes. Since donors are more willing to donate to countries whose policy choices are more aligned with their preferences, in order to maximize aid flows, conformity in policy-choices with the donor (even under full delegation) may be the equilibrium. Thus, even if real ownership may be a possibility, conformity will be more likely ("the H-street waltz").

We contribute to this literature both theoretically and empirically. Regarding theory, we analyze the transmission of information in the allocation of aid. To our knowledge, it is the first time that communication is explicitly introduced to the context of foreign aid. With respect to our empirical models, even though some papers have considered the importance of distinguishing among different types of aid flows and some have empirically investigated the determinants of budget support, we are the first to test whether such a choice is responsive to communication between the donor and the recipient.

\section{Theoretical framework}

Marchesi et al. (2011) show that context-specific knowledge is crucial to the design of the International Monetary Fund's (IMF) reform programs. Comparing the performance of a delegation scheme against a centralization scheme they find that program recipients' discretion in the choice of reforms (delegation) should only be increased when the country's local knowledge is strictly more important than those of the IMF. Conversely, centralization will be preferred when the IMF's knowledge is more important than local knowledge. Finally, a reduction in the conflict of interests between the IMF and the recipient may lead the Fund to give the recipient less freedom in designing reforms (centralization). This is because a decrease in the bias increases the amount of information transferred by the recipient to the multilateral institution in the centralization regime and thus the IMF's incentive to delegate may decrease. In this paper we adapt the same theoretical framework to the relationship between a donor (who can be bilateral or multilateral) and a recipient country. This section provides a sketch of the theoretical framework of Marchesi et al. (2011) that we adapt to our context.

In the model there are two players: a recipient country and a donor that agree about the choice of policies in the recipient country in exchange for aid, denoted by $p$. The recipient's welfare depends on its national income $Y(p)$ which in turn is a function of its policies $p$. Policies which maximize $Y(p)$, are denoted by $p^{*}$. We define $p^{*}$ to be those policies that are required to cover an output gap (i.e., the distance between the country's current level of output and its potential output). 
The donor and the recipient own some private information which are both required for the design of the optimal policies

$$
p^{*}=g+d
$$

where $g(d)$ is information observed only by the recipient (donor). The recipient's superior information over $g$ represents the local knowledge (for instance information about the country's economy and sociopolitical information about the preferences and the agenda of the government) and it can be seen as deriving from its closer proximity to the 'business environment' relative to the donor. On the other hand the donor's informational advantage $d$ is derived from the country-wide knowledge it accumulates during its activities (a fortiori when the donor is a multilateral organization). Both types of information are assumed to be soft, that is, they cannot be certified or "proved." 9

The donor is benevolent: it aims to reduce economic policy distortions in the recipient country by offering economic assistance contingent on the adoption of distortion-lowering policies. ${ }^{10}$ It maximizes the square of the distance between the implemented policy vector $p$ and the donor's preferred policy vector $p_{D}^{*}$ given by

$$
W^{D}=w^{D}-\left(p-p_{D}^{*}\right)^{2}
$$

In turn, the recipient maximizes

$$
W^{G}=w^{G}-\left(p-p_{G}^{*}\right)^{2},
$$

which is monotonically decreasing in the distance between the policy $p$ that is actually implemented, and the recipient's preferred policy $p_{G}^{*}$. The optimal policy of the recipient deviates from the optimal policy given by (2) in the sense that

$$
p_{L}^{*}=p^{*}-b .
$$

The recipient government cares about its national income, but its choice may be constrained by the influence of some interest groups benefitting from structural distortions (e.g., Drazen

\footnotetext{
${ }^{9}$ Both $g$ and $d$ are random variables and they are independently and uniformly distributed on the interval $[0, G]$ and $[0, D]$, respectively. The informational advantage of the recipient (donor) increases with the size of the respective interval.

${ }^{10}$ It is assumed that the donor cares about the well-being of all recipients, while the recipient is only interested in its own benefit. Moreover, when the donor is a multilateral institution this objective is strengthened and complemented by the desire to reduce the negative effects (or to increase the positive effects), due to potential spillovers of domestic policies on global output (see below).
} 
2002). $b>0$ captures the extent to which the policy choice of the recipient may deviate from its optimal level due to the pressures of interest groups opposing policy reforms. More generally, conflicts of interest over desired policy may reflect various causes (among others, Tabellini and Alesina 1990, Alesina and Drazen 1991, Fernandez and Rodrik 1991) and, in principle, they could also influence the donor's decisions. In this paper, however, in order to focus on the issue of communication, we assume a benevolent donor, in contrast to a recipient which we assume to be more responsive to private interests.

Similarly, the optimal policy of donor $p_{D}^{*}$ differs from the optimal policy in the sense that

$$
p_{D}^{*}=p^{*}+e,
$$

with $e>0$. A possible interpretation of $e$ is due to the existence of some externalities derived from the recipient's policies. Recipients do not generally internalize the impact of their policies on their neighbors (see, for example, spillovers arising from exchange rate policy, capital flows, financial regulation or climate change). This may generate some conflicts of interest between the recipient and the donor, especially in the case of a multilateral institution which might aim to internalize spillovers (Rajan 2008). ${ }^{11}$ Following from (4) and (5), the difference in optimal policies $\left(p_{D}^{*}-p_{G}^{*}=e+b=B\right)$ reflects the extent of the policy bias, denoted by $B$.

\subsection{Communication game}

The communication game follows Crawford and Sobel (1982), as outlined in more detail in Appendix A. The game is played in three stages: allocation of control rights, communication, and program implementation. ${ }^{12}$ In the first stage, the donor either allocates authority over the choice of the adjustment program to the recipient (delegation) or it retains authority for itself (centralization). We assume that the state of the world is revealed after the first stage of the game (allocation of control rights). The game then moves to the communication stage. Under delegation, the donor sends a message to the recipient concerning its private knowledge of the state of the world. The recipient now has to update its beliefs and chooses

\footnotetext{
${ }^{11}$ In reality it might also be that donors care about the spillover effects of recipients' policies on their own markets or on the availability of natural resources; but since we are assuming the donor is benevolent we neglect any concern it could have for its private interests. However, e could also be modified to represent these possible alternative concerns.

${ }^{12}$ We have in mind a situation in which both the donor and the recipient cannot commit to an incentivecompatible decision rule in which the Revelation Principle applies. We believe this assumption fits in well with the specific relationship between a donor and a recipient country in the process of designing reform programs in which the principal cannot use a standard mechanism to elicit private information from the agent.
} 
policies. Under centralization, the recipient sends a message to the donor concerning its local knowledge. The donor similarly has to update its beliefs and chooses policies. Finally, outcomes are realized.

In the communication equilibrium, under delegation, the recipient only learns the interval to which the realization of $d$ belongs, and so obtains partial information about the donor's private knowledge. The smaller the size of the partition interval, the more informative the donor's message. Following Crawford and Sobel (1982), an informative equilibrium always exists in which the number of intervals $N$ is maximal (focal equilibrium). Denoting $N(D, B)$ the maximum number of intervals, the donor's ex ante expected welfare (loss), is given by

$$
L_{D}^{D}(N, B, D)=B^{2}+\sigma_{D}^{2}
$$

where

$$
\sigma_{D}^{2} \equiv \frac{D^{2}}{12 N^{2}}+\frac{B^{2}\left(N^{2}-1\right)}{3},
$$

is the ex-ante residual variance of $d$, that is the uncertainty about $d$ faced by the recipient before being reported by the donor the equilibrium signal. In the focal equilibrium, given the bias $B, \sigma_{D}^{2}$ (and with it the donor's expected loss) increases with $D$, that is with the importance of the donor's private information. Under delegation, the donor's private information is not fully exploited and so its expected loss increases with its informational advantage $D$. Finally, for any given $D$ the maximum precision of the information transmitted by the donor decreases with the bias $B$. To put this differently, the extent and quality of information transmission depends on how close the preferences of the donor and of the recipient are: the larger the bias $B$, the less precise the cheap talk will be.

The structure of the communication game, under centralization, is symmetric to the delegation case where the recipient is now the sender and the donor the receiver. The donor, knowing $d$ and having received a signal from the recipient, now chooses the policy vector $p$. The donor's ex ante expected loss (in the focal equilibrium) is now given by

$$
L_{C}^{D}(N, B, G)=\sigma_{G}^{2}
$$

where

$$
\sigma_{G}^{2} \equiv \frac{G^{2}}{12 N^{2}}+\frac{B^{2}\left(N^{2}-1\right)}{3},
$$

is the ex ante residual variance of $g$, that is the uncertainty faced by the donor before it receives the equilibrium value of the signal sent by the recipient. In the focal equilibrium, given the bias $B, \sigma_{G}^{2}$ (and the donor's expected loss) increases with $G$, that is with the 
informational advantage of the recipient. Centralization avoids the agency bias but it results in an under-use of the recipient's information.

Therefore, the donor determines whether or not to retain its control rights over policies by comparing its ex ante expected loss under delegation (that is, $L_{D}^{D}(N, B, D)$ ) with its expected loss under centralization (that is, $L_{C}^{D}(N, B, G)$ ). Since they are increasing in $D$ (under delegation) and in $G$ (under centralization), respectively, there will be threshold values of $D$ and $G$ corresponding to the choice of each regime. The choice will then depend on the size of the conflict of interest $(B)$ and the relative importance of the two players' informational advantage $(G, D)$.

In particular, the donor always maintains centralization whenever its private information is more important than the agent's private information (that is, $D>G$ ). Alternatively, the donor will choose delegation not only when the recipient's private information $G$ is (strictly) greater than $D$ but $G$ should also be greater than some threshold level $(D(G, B))$. Therefore, due to the policy bias, the donor will (optimally) choose centralization even when its informational advantage is smaller than $G$, but greater than such threshold value. In this case the elimination of the bias and the full use of the donor's knowledge will more than compensate the loss related to the under-use of the recipient's information.

In general, an increase in $B$ has two different effects, a direct and an indirect one. The direct effect is to increase the agency problem, thus reducing the donor's willingness to delegate. The indirect effect concerns communication: it reduces the amount of information transferred by the donor to the recipient under delegation (leading to centralization) and the amount of information transferred by the recipient to the donor under centralization (leading to delegation). ${ }^{13}$ The prevailing effect is a priori undetermined.

\section{The empirical model}

The theoretical model provides normative indications regarding the allocation of control rights over policy actions in the donor-recipient relationship. This section empirically investigates the role of information transmission for the actual design of policies. The model predicts that delegation should prevail when the importance of the recipient's knowledge dominates the size of the bias and the importance of the donor's private information. On the contrary, centralization should prevail when either the importance of the donors' knowledge or the size of the agency bias dominates the role of the recipient's local knowledge.

\footnotetext{
${ }^{13}$ The derivative of $D(G, B)$ with respect to $B$ cannot be analytically derived and is obtained by numerical simulations (see Harris and Raviv 2008).
} 
Since budget support increases the involvement of recipient governments in the decisionmaking process, it is an example of "delegation" in the sense of our model. Aid in the form of budget support is directly given to the recipient, so that control over the aid money rests with the government of the recipient country rather than the donor. Alternatively, as project aid represents a more "centralized" type of aid, it is a good example for a more centralized provision of aid. Projects are usually closely supervised, or even directly implemented, by the donor, thus leaving less influence for the recipient government. ${ }^{14}$

When controlling for countries' characteristics and their economic performance (and for donors' political motivations), we empirically investigate whether or not the choice of these two types of aid is affected by variables related to the transmission of information. Specifically, we expect to find budget support to be preferred in countries whose local knowledge is more important than the donor's knowledge and the agency bias. Conversely, we expect that project aid (or centralization) will prevail when the donors' information is more relevant.

\subsection{Method and Data}

We examine the determinants of budget aid and project aid over the 1995-2010 period and a maximum of 120 countries, due to data availability. ${ }^{15}$ We estimate separate regressions for the two types of aid rather than using, e.g., the ratio of the two, which could reflect their relative importance in one regression. The reason is that many countries receive no aid at all, while others receive aid in only one of the two types. Zero aid could then not be separated from aid of the category we would put on the numerator; zero aid in the denominator would make the share approach infinity. We avoid both problems by treating the two types of aid in separate regressions.

The regressions are estimated using Poisson Pseudo Maximum Likelihood (PPML). As Santos Silva and Tenreyro (2006) argue, PPML outperforms OLS and Tobit approaches with heteroskedasticity and many zero observations in the data. PPML is frequently used for non-count data in the recent international economics literature (see Berger and Nitsch 2008, Egger and Larch 2011, among many others). ${ }^{16}$ We estimate the model with conditional coun-

\footnotetext{
${ }^{14}$ This assumes that aid is less than fully fungible, which finds support in the recent literature. For example, Van de Sijpe (2013: 26) shows "little evidence that aid is fully or even largely fungible; rather, most point estimates suggest limited fungibility."

${ }^{15}$ Data on general budget support and project aid are from the DAC's Creditor Reporting System (CRS, OECD 2012). These data are not reported for years prior to 1995.

${ }^{16}$ The use of Tobit and Heckman - two commonly used methods in the aid allocation literature - would be problematic with our data (see Sigelman and Zeng 1999). Tobit may lead to biased estimates when the zeros are not the result of censoring mechanisms, while Heckman is inefficient when the dependent variable is exclusively nonnegative.
} 
try fixed effects (clustering the standard errors appropriately), include year fixed effects, and lag the explanatory variables by one year: ${ }^{17}$

$$
P_{i, t}=\exp \left(\beta_{1} X_{i, t}+\eta_{i}+\tau_{t}+u_{i, t}\right)
$$

and

$$
B_{i, t}=\exp \left(\beta_{1} X_{i, t}+\eta_{i}+\tau_{t}+u_{i, t}\right)
$$

where $P_{i, t}$ and $B_{i, t}$ represent the amount of project aid and budget aid committed in constant 2009 million US dollars to country $i$ in year $t$, and $X$ is a vector containing the variables introduced below. Finally, $\eta_{i}$ and $\tau_{t}$ are country and year fixed effects, respectively, and $u_{i, t}$ is the error term.

Our variables of interest are the so-called "informational variables." Such variables are meant to capture the impact of the agency bias, the donor country's general knowledge and the recipient country's local knowledge on the optimal amount of reforms. We introduce them in turn.

Agency bias. The bias in the objective function of the recipient country's authorities is due to political and economic reasons, while the bias in the donor's objective function arises from the externalities induced by the recipient's policy choice. According to the literature on political economy, measures of political instability, polarization and social division (e.g., Tabellini and Alesina 1990, Alesina and Drazen 1991) ${ }^{18}$ should account for a country's "resistance" against reforms (or status quo bias). With this in mind, in order to capture the recipient country's status quo bias in the empirical model, we considered measures of "institutional capacity" and "socioeconomic complexity." In this respect we included some of the International Country Risk Guide's (ICRG) indicators: government stability, bureaucratic quality, and ethnic tensions. Government stability ranges from zero to 12, bureaucratic quality from zero to four, and ethnic tensions from zero to six, with higher values showing "better" environments. High scores in bureaucratic quality indicate that the bureaucracy has the strength and expertise to govern, without the necessity for drastic changes in policy or interruptions in government services. Government stability is "a measure of the government's capability in carrying out its declared programs/policies and its ability to stay in office." Ethnic tensions

\footnotetext{
${ }^{17}$ We use the user-programmed Stata ado file xtpqml programmed by Tim Simcoe.

${ }^{18}$ In Tabellini and Alesina (1990), given a situation of political instability and polarization, a balanced budget does not represent a political equilibrium. This is because the current majority does not internalize the costs of budget deficits and the more this is the case, the greater the difference between its preferences and the expected preferences of future majorities. Alesina and Drazen (1991) find that when stabilization has significant distributional implications a "war of attrition" among different socioeconomic groups may delay stabilization.
} 
measure "the degree of tension within a country which can be attributable to racial, cultural and language divisions" (PRS Group 1998). ${ }^{19}$

Moreover, we also considered a measure of both economic and financial openness since the divergence of interests between the donor and recipient country may also depend on the existence of some externalities generated by the recipient's policy choices, which in turn will be more relevant as trade and cross-border capital flows increase. ${ }^{20}$ Specifically, we include the KOF Index of Globalization. This index is widely used as an indicator of openness and consists of 23 components including openness to trade and capital flows, actual flows, but also globalization related to the exchange of information and political globalization. The index ranges between 1-100, with higher values indicating more globalization. ${ }^{21}$

Theoretical predictions of the effect of the agency bias on the extent of reforms are not clear-cut. As we described above, an increase in the agency bias has both direct and indirect effects which, in principle, could either reduce or increase the incentive to delegate.

Recipient's local knowledge. The importance of a recipient's local knowledge is supposed to be crucial for less transparent countries and for countries with a more complex socioeconomic structure. In order to measure the importance of a recipient's local knowledge, our main index follows Hollyer et al. (2011), who suggest missing data on standard economic indicators (like inflation, etc.) as indicators of (lack of) transparency. Rather than choosing any arbitrary data series we evaluate all 1260 series included in the World Bank's World Development Indicators (2013). Our resulting transparency indicator shows the share of series for which there are data available in a given country and year.

The less reliable or detailed the available information, the more detailed the required monitoring by the donor in principle should be. As a consequence, donors will tend to give priority to project aid as compared to budget aid. However, given the lack of information, the donor might as well give greater control to the recipient, since in such situations the recipient is likely to know better which type of reforms are likely to work and which are not. If this is the case, donors will prefer budget aid to project aid. By increasing the recipient's

\footnotetext{
${ }^{19}$ We tried to control for some of the other ICRG indicators, such as corruption, rule of law, investment profile and social conditions, and our results remain unchanged. We also tried to include "education" (proxied as "primary school enrollment") but missing data reduced the sample substantially, so we do not report the results below.

${ }^{20}$ Namely, policies in one country may impose externalities on others, especially trade and exchange rate policies.

${ }^{21}$ See Bjørnskov and Potrafke (2011), Gassebner et al. (2011) and Potrafke (2011). Instead of the KOF Index we also included the sum of a country's imports and exports (relative to GDP). Our results are unchanged.
} 
control over policies, the donor manages to exploit the private information held by the recipient in order to achieve deeper reforms. As an indicator of socioeconomic complexity we use "ethnic tensions" from the ICRG introduced above. Since an increase in the relevance of local knowledge $G$ enhances the incentive to delegate, we expect the amount of budget support to increase and the amount of project aid to decrease with $G$.

The donor's specific knowledge. A recipient country having a poor quality of government staff could be a reason for a recipient to seek a donor's technical advice. This fact could explain project aid rather than budget aid. In order to capture this, we included the index of "bureaucratic quality." Finally, the donor's informational advantage will be more relevant for more open countries to the extent that the donors care about international spillovers. We employ the KOF Index of Globalization introduced above to test for this hypothesis. As the donor's informational advantage $D$ increases the incentives to centralize decisions, we expect to find that project aid increases with $D$.

We provide the details of the definitions and sources of the variables included in the regressions and descriptive statistics in Appendices D and E. Appendix F shows the correlations of the variables included in the analysis. Clearly, some of the variables refer to both the influence of the agency problem and the importance of the recipient's or donor's knowledge. Since the impact of such indicators could have conflicting effects, in these cases the signs of the coefficients will tell us the "net effect," i.e., the impact that dominates.

Our choice of control variables follows the literature on the determinants of aid allocation. Most of this literature has evaluated whether and to what extent commercial and political donor interests have shaped the allocation of aid, but the role of recipient country "need" and "merit" have also featured prominently. Regarding the importance of political motives, the recent analysis of Faye and Niehaus (2012) shows that donors' political allies receive more aid prior to an election. Kuziemko and Werker (2006) and Dreher et al. (2009a, 2009b) find that countries receive more aid when they are temporary members of the United Nations Security Council (UNSC). Berger et al. (2013) show that successful CIA interventions also increase the amount of foreign aid a country receives. Concerning commercial interests, Berthèlemy and Tichit (2004) report that bilateral trade intensity has a strong impact on the allocation of aid. ${ }^{22}$ At the same time, Dollar and Levin (2006) and Claessens et al. (2009) show that donors are to some extent altruistic by targeting aid at poor recipient countries with sound economic policies and institutions.

\footnotetext{
${ }^{22}$ See also Berthélemy (2006) and Höffler and Outram (2011).
} 
Following this literature we control for (log) GDP per capita to take account of development, the World Bank's Country Policy and Institutional Assessment (CPIA) as indicator of the quality of policies and institutions, the share of votes in a year that a country votes in line with the United States in the United Nations General Assembly (UNGA) to capture the largest donor's geo-strategic interests, and (log) trade with the United States to proxy for its commercial interests. As the dependent variable is not in per capita terms, we also control for the $(\log )$ size of the recipient countries' population. ${ }^{23}$

We take per capita GDP (measured in constant 2000 US dollars) and population from the World Bank's (2013) World Development Indicators database. The CPIA is also provided by the World Bank and assesses the conduciveness of a country's policy and institutional framework to poverty reduction, sustainable growth, and the effective use of development assistance. The CPIA groups 16 criteria into four clusters that are equally weighted to derive the overall CPIA rating. ${ }^{24}$ Trade flows are the sum of exports and imports (in constant 2005 1000 USD), taken from the UN Comtrade Database, while UNGA voting is calculated based on data from Strezhnev and Voeten (2013).

\section{$5 \quad$ Estimation results}

We report the main results in Table 1. Column 1 shows the results for project aid excluding our variables of interest, while column 2 shows those for budget aid instead. ${ }^{25}$ As can be seen, most of the control variables are not significant at conventional levels, the exception being the World Bank's CPIA score. The insignificance of per capita GDP, population size, voting with the United States in the UNGA and trade with the US are not surprising. ${ }^{26}$ Contrary to most of the aid allocation literature, we estimate rather conservative models, which include recipient country and year fixed effects. ${ }^{27}$ What is more, we investigate aid by

\footnotetext{
${ }^{23} \mathrm{We}$ also tried a number of alternative variables to test for the robustness of our results. These include the rate of inflation, GDP growth, domestic (fixed) investment (to GDP), government consumption (to GDP), total debt service (to exports), and the Polity IV index of democracy (see Marshall and Jaggers 2009). Our main results are not affected by their inclusion.

${ }^{24}$ These criteria include economic management, structural policies, policies for social inclusion and equity, and public sector management and institutions.

${ }^{25}$ Note that the regressions using budget aid as a dependent variable contain fewer observations than those pertaining to project aid. This is because countries not receiving any aid in a category over the whole sample period have to be excluded in the fixed effects regressions.

${ }^{26}$ Similar results (i.e., insignificant coefficients) were obtained controlling also for temporary membership in the UNSC, proximity to France, Germany and the United Kingdom in the UNGA, and commercial ties with France, Germany, the United Kingdom and Japan.

${ }^{27}$ See, for example, Alesina and Dollar (2000), Dollar and Levin (2006), Nordtveit (2012). When we estimate PPML without conditional country fixed effects we find project and budget aid to decrease with per capita GDP, and to increase with a country's CPIA score and its population size. Greater trade with
} 
all rather than aid from a particular donor, so the strategic motives of a particular donor do not necessarily shape the allocation of total aid, even if they are important for this particular donor. Finally, most of the previous literature focuses on aid for all purposes rather than budget aid and project aid as we do.

The coefficients shown represent incidence rate ratios. Their interpretation is straightforward - they show the relative change of the dependent variable for a one-unit change of the explanatory variable. Coefficients larger then one represent increases while coefficients smaller than one imply decreases. For example, the coefficient of 1.3 for the CPIA score in column 1 implies that project aid increases by a factor of 1.3 with an improvement of the CPIA score of one point (the average being 3.3 in the regression of column 1). This increase is significant at the five percent level. Column 2 shows that a corresponding increase in the CPIA score increases budget aid by a factor of 1.8, at the one percent level of significance.

Columns 3 and 4 include our variables of interest, thus mirroring the specifications of equations (10) and (11). As can be seen, the results are in line with our hypotheses regarding the effect of the informational variables on the provision of aid. At the ten percent level of significance, the amount of project aid increases with greater transparency, while transparency does not affect budget aid at conventional levels of significance. This is in line with the predictions of our model: since transparency indicates the importance of the recipient's knowledge as compared to the donor's knowledge, more transparent countries receive more project aid but not budget aid, as the theory implies. ${ }^{28}$ Quantitatively, an increase in transparency of 0.1 (the mean being 0.67 in column 3) increases project aid by 42 percent. Clearly, this is an economically relevant magnitude.

At the one percent level, project aid decreases with bureaucratic quality, while the quality of a recipient's bureaucracy does not affect budget aid. This is consistent with our theoretical prediction, according to which centralization could dominate delegation when the bias of the recipient countries' authorities, relative to the donor, is too large. Indeed, for countries with a lower quality of government officials, the importance of the donor's knowledge increases, which also leads to more centralization. Quantitatively, an increase in bureaucratic quality by one point on the twelve-point scale decreases the amount of project aid by about 12

the US increases budget aid, but not project aid. These additional results are available on request.

${ }^{28} \mathrm{We}$ also included the number of telephone lines (per 100 people) and an index of press freedom as additional proxies for the availability of information. Phone lines are never significant at conventional levels, while the amount of project aid increases with press freedom in two of our specifications, at the ten percent level of significance. The coefficient of press freedom is negative, but insignificant, for budget aid. As the model predicts, more project aid is preferred when local information is less important (i.e., with more press freedom). Our main results are not affected by the inclusion of these additional variables. 
percent. On the contrary, the coefficient of the globalization index, which is also a proxy for the importance of the donor's information as well as an indicator of the donor's bias with respect to the recipient, is not significant at conventional levels.

The amount of budget aid rises with the absence of ethnic tensions, at the one percent level of significance, while project aid is not significantly affected. Quantitatively, an improvement in the variable indicating the absence of ethnic tensions by one point increases budget aid by more than 26 percent. Since for all ICRG indices higher scores indicate "better" environments, the smaller the degree of tensions within a country attributable to race, nationality or language, the more delegation is preferred. This effect may be explained by the greater room for delegation when, as suggested in the political economy literature, ethnic tensions may reflect a greater status quo bias by that recipient country. However, it is also true that when a country is more multifaceted from a social point of view and, consequently, its local knowledge is more important, delegation should also be the preferred scheme. Therefore, since ethnic tensions are related to both the importance of information and the importance of the bias, in order to disentangle these two effects we interact ethnic tensions with the indicator of transparency. We expect the effect of "ethnic tensions" on budget aid to increase with transparency: the more transparent a country is, the less crucial its local information and the less budget aid (i.e., less delegation) should be preferred when the bias increases (i.e., less "absence of ethnic tensions"). Symmetrically, we expect the effect of "ethnic tensions" on project aid to decrease with transparency: only when a country is transparent (and local information is not crucial) project aid (i.e., centralization) should be preferred when the bias increases (and vice-versa).

The results from columns 5 and 6 in Table 1 confirm such intuition: the coefficient of the interaction variable is larger than one and significant at the ten percent level for budget aid, while the coefficient for project aid is smaller than one and highly significant. As is well known, interpreting the significance of interaction effects in nonlinear models such as Poisson is not straightforward (Ai and Norton 2003, Greene 2011). However, these difficulties do not pertain to incidence rate ratios, which rely on a multiplicative rather than additive scale (Buis 2010). In this case, the interaction simply reflects the ratio of the odds ratios of the two interacted variables (which do not depend on the values of the other variables in the model) and the significance of the incidence ratio can be directly calculated. However, as we are interested in how the marginal effect of ethnic tensions changes over the range of transparency, we next calculate the average marginal effects. We show the results for project aid in Figure 1 and those for budget aid in Figure 2, together with the 90-percent confidence interval. Figure 1 shows that the marginal effect of "ethnic tensions" on the amount of 
project aid decreases with transparency, as the theory predicts. Turning to budget aid, Figure 2 shows that the marginal effect of ethnic tensions on the amount of budget aid is not significant when transparency is low. With high transparency though, the marginal effect of ethnic tensions becomes positive and significant at the five percent level, which implies that budget aid decreases with a larger bias, as expected.

Let us next turn to the impact of government stability. As can be seen, the coefficient of government stability is not significant at conventional levels in any of the regressions. According to our theory, lower government stability should lead to higher (lower) amount of project (budget) aid, as one would expect centralization to be higher in more unstable countries. This argument, however, overlooks the fact that an increase in the bias also has the effect of reducing the amount of communication under centralization, thus making such a decision more costly. These countering effects could lead to an on average insignificant coefficient. In order to disentangle these two effects, we again introduce interaction terms, between government stability and the indicator of transparency. As above, we expect to find the effect of government stability on project aid to decrease with transparency: only for a high degree of transparency a larger bias should lead to more project aid (and vice-versa).

We show the results in columns 7 and 8. As can be seen, the effect of government stability on project aid decreases with transparency, at the five percent level of significance, while there is no significant interaction effect on the amount of budget aid. We report the marginal effects in Figures 3 and 4. Figure 3 shows that the results support the theory stated above: the amount of project aid a country receives increases significantly with greater stability when transparency is low, but decreases with stability when transparency is high. Thus, project aid will be desirable with a larger bias only when transparency is high (that is when local knowledge is less important). This finding also supports the theory. Regarding budget aid, Figure 4 shows that the marginal effect of government stability is flat and does thus not significantly depend on the level of transparency. ${ }^{29}$

In summary, the empirical analysis confirms that the importance of donors' private information influences the amount of project aid, while recipients' local knowledge is positively correlated with the amount of budget support. Concerning the effect of the agency bias, since an increase in the bias can at the same time have both a direct and an indirect effect, its overall impact on the optimal amount of each aid scheme is a priori undetermined. The next section provides policy implications and concludes.

\footnotetext{
${ }^{29}$ We should stress here that the influence of the agancy bias on the amount of budget aid and project aid is also consistent with the (theroretical) results of Cordella and dell'Ariccia's (2007) who find that budget support shoud be preferred to project aid when the donor's preferences are close to those of the recipient.
} 
Table 1: Project aid and budget support, 1995-2010, PPML

\begin{tabular}{|c|c|c|c|c|c|c|c|c|}
\hline & $\begin{array}{c}(1) \\
\text { project }\end{array}$ & $\begin{array}{c}\text { (2) } \\
\text { budget }\end{array}$ & $\begin{array}{c}(3) \\
\text { project }\end{array}$ & $\begin{array}{c}\text { (4) } \\
\text { budget }\end{array}$ & $\begin{array}{c}\text { (5) } \\
\text { project }\end{array}$ & $\begin{array}{c}\text { (6) } \\
\text { budget }\end{array}$ & $\begin{array}{c}(7) \\
\text { project }\end{array}$ & $\begin{array}{c}\text { (8) } \\
\text { budget }\end{array}$ \\
\hline \multirow[t]{2}{*}{ GDP per capita (t-1) } & 0.662 & 2.398 & 0.574 & $4.821^{* *}$ & 0.592 & $4.257^{* *}$ & 0.563 & $4.789^{* *}$ \\
\hline & $(0.115)$ & $(0.247)$ & $(0.123)$ & $(0.031)$ & $(0.146)$ & $(0.046)$ & $(0.118)$ & $(0.042)$ \\
\hline \multirow[t]{2}{*}{ CPIA (t-1) } & $1.289^{* *}$ & $1.830^{* * *}$ & $1.248^{* *}$ & 1.431 & $1.197^{*}$ & $1.525^{*}$ & $1.244^{* *}$ & 1.427 \\
\hline & $(0.015)$ & $(0.002)$ & $(0.049)$ & (0.149) & $(0.098)$ & $(0.093)$ & $(0.046)$ & $(0.187)$ \\
\hline \multirow[t]{2}{*}{ (log) Population (t-1) } & 2.486 & 0.636 & 3.323 & 0.302 & 2.510 & 0.248 & 2.870 & 0.300 \\
\hline & $(0.155)$ & $(0.738)$ & $(0.155)$ & $(0.445)$ & $(0.245)$ & $(0.357)$ & $(0.201)$ & $(0.446)$ \\
\hline \multirow[t]{2}{*}{ Voting with USA (t-1) } & 1.774 & 1.042 & 2.545 & 0.808 & 2.056 & 1.160 & 2.318 & 0.814 \\
\hline & $(0.303)$ & $(0.974)$ & $(0.165)$ & $(0.898)$ & $(0.279)$ & $(0.931)$ & $(0.192)$ & $(0.897)$ \\
\hline \multirow[t]{2}{*}{ Trade with USA (t-1) } & 1.006 & 0.945 & 1.011 & 0.963 & 1.022 & 0.943 & 1.022 & 0.962 \\
\hline & $(0.880)$ & $(0.676)$ & $(0.855)$ & $(0.848)$ & $(0.702)$ & $(0.756)$ & $(0.726)$ & $(0.848)$ \\
\hline \multirow[t]{2}{*}{ Government Stability (t-1) } & & & 0.987 & 0.987 & 0.995 & 0.985 & $1.305^{* *}$ & 0.962 \\
\hline & & & $(0.500)$ & $(0.909)$ & $(0.759)$ & $(0.892)$ & $(0.048)$ & $(0.933)$ \\
\hline \multirow[t]{2}{*}{ Ethnic Tensions ( $\mathrm{t}-1)$} & & & 0.951 & $1.262^{* * *}$ & $2.035^{* * *}$ & 0.402 & 0.956 & $1.261^{* * *}$ \\
\hline & & & $(0.397)$ & $(0.002)$ & $(0.001)$ & $(0.123)$ & $(0.413)$ & $(0.004)$ \\
\hline \multirow[t]{2}{*}{ Bureaucratic Quality (t-1) } & & & $0.884^{* *}$ & 0.976 & $0.903^{*}$ & 0.931 & $0.895^{* *}$ & 0.977 \\
\hline & & & $(0.017)$ & $(0.899)$ & $(0.070)$ & $(0.730)$ & $(0.038)$ & $(0.905)$ \\
\hline \multirow[t]{2}{*}{ Globalization Index (t-1) } & & & 1.008 & 0.983 & 1.007 & 0.982 & 1.009 & 0.983 \\
\hline & & & $(0.593)$ & $(0.470)$ & $(0.599)$ & $(0.471)$ & $(0.525)$ & $(0.421)$ \\
\hline \multirow[t]{2}{*}{ Transparency (t-1) } & & & $4.197^{*}$ & 7.651 & $176.328^{* * *}$ & 0.031 & $135.824^{* * *}$ & 5.444 \\
\hline & & & $(0.065)$ & $(0.412)$ & $(0.000)$ & $(0.321)$ & $(0.008)$ & $(0.798)$ \\
\hline \multirow[t]{2}{*}{ Ethnic Tensions*Transparency, $\mathrm{t}-1$} & & & & & $0.340^{* * *}$ & $5.109^{*}$ & & \\
\hline & & & & & $(0.000)$ & $(0.057)$ & & \\
\hline \multirow[t]{2}{*}{ Gov. Stability ${ }^{\star}$ Transparency, $t-1$} & & & & & & & $0.667^{* *}$ & 1.040 \\
\hline & & & & & & & $(0.039)$ & $(0.961)$ \\
\hline Number of observations & 1631 & 1414 & 1059 & 912 & 1059 & 912 & 1059 & 912 \\
\hline Number of countries & 120 & 100 & 79 & 65 & 79 & 65 & 79 & 65 \\
\hline
\end{tabular}

Notes: Poisson Pseudo Maximum Likelihood (PPML) with conditional country fixed effects and

clustered standard errors, including year fixed effects. Incident Rate Ratios reported. p-values in parentheses; $* * *(* *)$ : significant at the one (five, ten) percent level. 
Figure 1: Project aid, bias and transparency I, 1995-2010

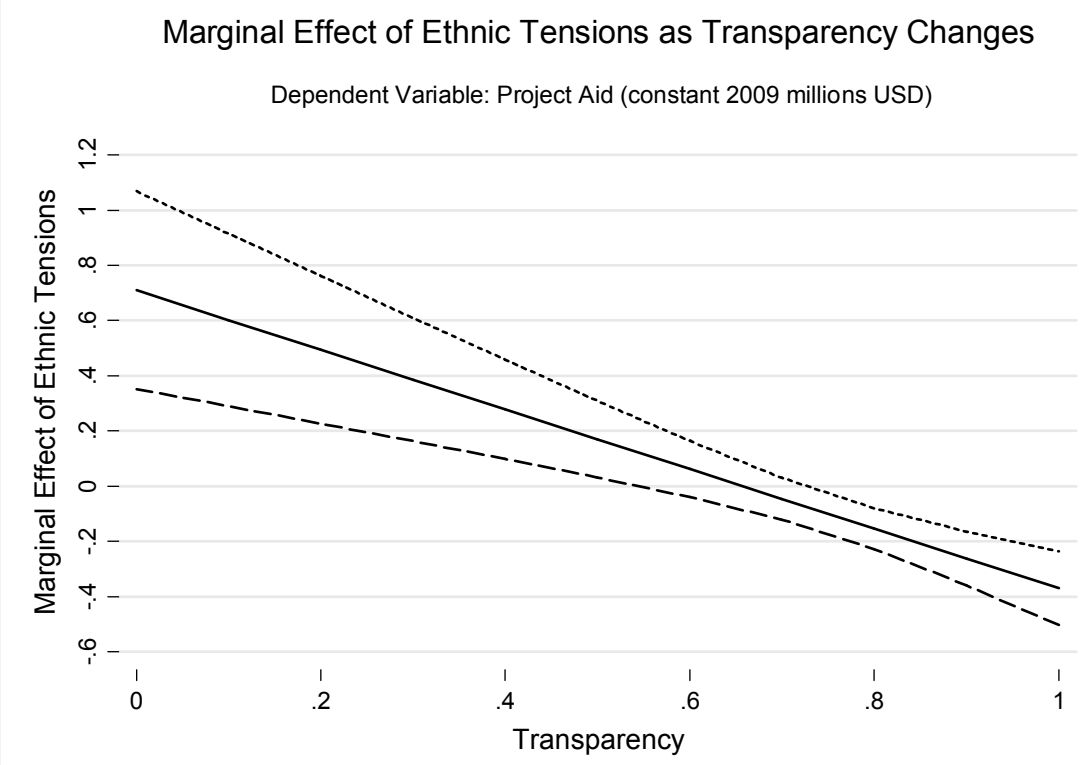

Notes: 90 percent confidence interval shown. Corresponds to regression of column 5 in Table 1.

Figure 2: Budget aid, bias and transparency I, 1995-2010

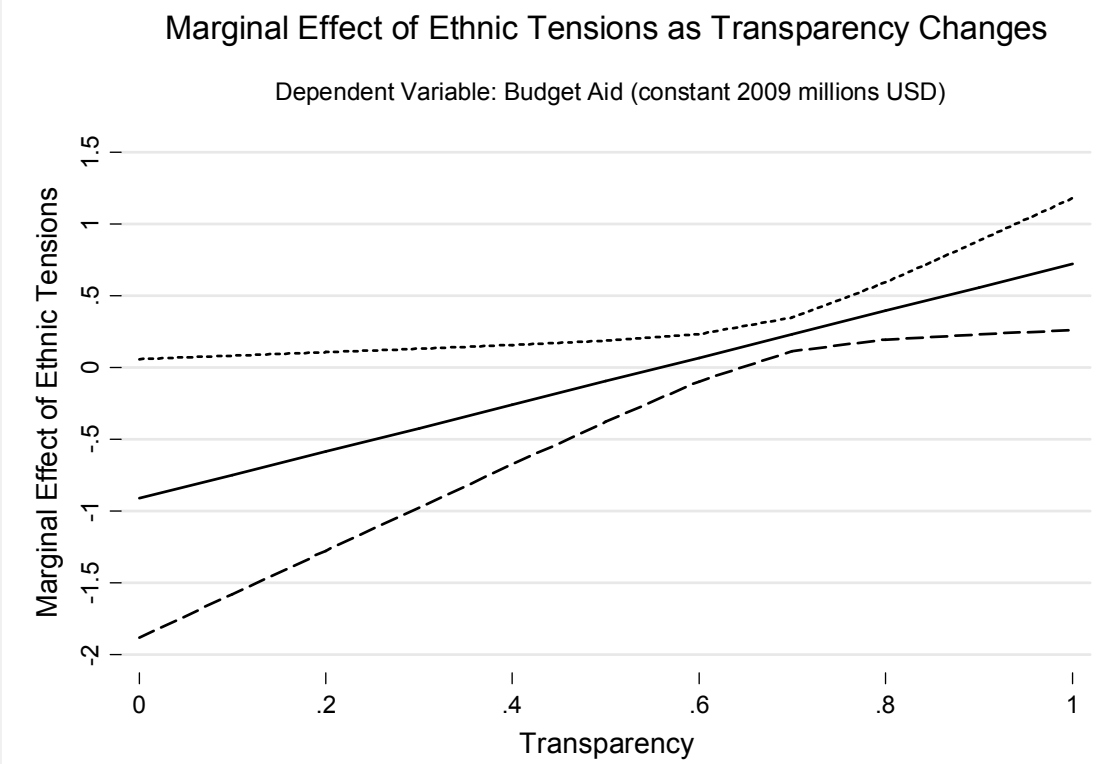

Notes: 90 percent confidence interval shown. Corresponds to regression of column 6 in Table 1. 
Figure 3: Project aid, bias and transparency II, 1995-2010

Marginal Effect of Government Stability as Transparency Changes

Dependent Variable: Project Aid (constant 2009 millions USD)

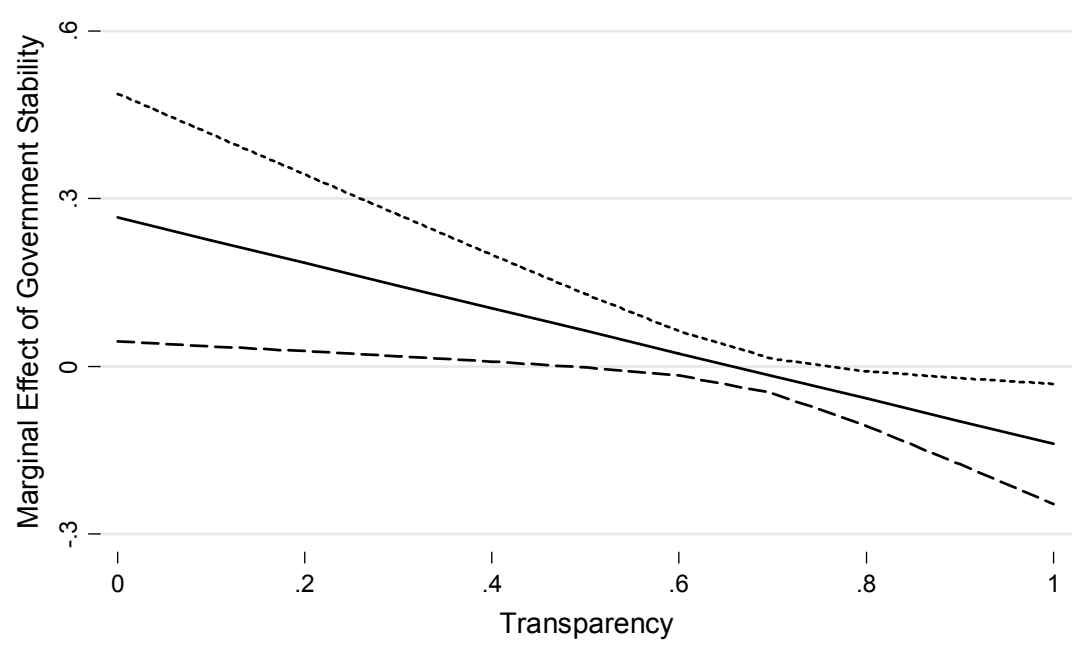

Notes: 90 percent confidence interval shown. Corresponds to regression of column 7 in Table 1.

Figure 4: Budget aid, bias and transparency II, 1995-2010

Marginal Effect of Government Stability as Transparency Changes

Dependent Variable: Budget Aid (constant 2009 millions USD)

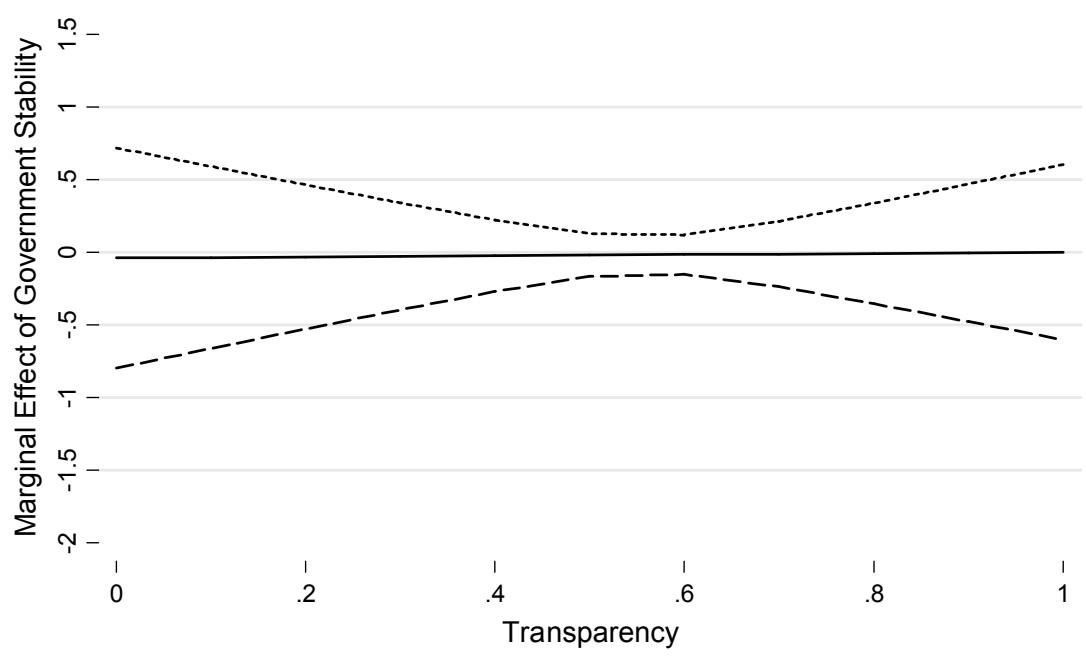

Notes: 90 percent confidence interval shown. Corresponds to regression of column 8 in Table 1. 


\section{Conclusions}

In this paper we have explored the role of information transmission between a donor and a recipient country in explaining how donors allocate budget aid and project aid. As in Marchesi et al. (2011), by relating the quality of the information supplied by a recipient country to the donor (and vice-versa) to the misalignment of interests between the two agents, we analyzed the properties of different aid schemes relative to the quality of the transmitted information. More specifically, we have compared an aid scheme in which control rights over policies are allocated to the donor, i.e., centralization (or project aid), with an aid scheme in which the recipient is left with more freedom to devise its own policy actions, ultimately being judged by policy outcomes, i.e., delegation (or budget support).

The main theoretical findings are as follows. For a given agency bias, when recipients' local knowledge is more important than the donors' information their discretion in the choice of reforms (delegation) should be increased. Conversely, there should be less freedom in designing reforms (centralization) when the donors' information is more relevant. The impact of the agency bias on determining the optimal lending scheme remains a priori undetermined as it can a have at the same time two countervailing effects (a direct and an indirect one).

In the empirical section, we focused on two distinct ways of delivering aid, budget support and project aid. Budget support increases the involvement of the recipient governments in the decision-making and is thus an example of delegation. Conversely, project aid represents a more centralized type of aid. We investigated the role of the relative importance of donor and recipient information in determining which aid scheme is preferred. Controlling for countries' characteristics and their economic performance (and for the possible political motivations for granting aid) we find that the importance of donors' private information does influence the amount of project aid while recipients' local knowledge is positively correlated with the amount of budget support.

Our model suggests that donors who allocate aid taking properly account of information and preferences will achive the results they aim for more effectively. Whether an allocation of aid in line with the model is likely to increase economic growth or reduce poverty depends on whether, as we assume, the donor is sufficiently benevolent. According to the aid effectiveness literature, however, both project aid and budget aid have not on average been effective with respect to achieving growth (e.g., Rajan and Subramanian 2008). This could imply that donors in reality allocate aid in line with other, geopolitical or commercial, targets. ${ }^{30}$ It

\footnotetext{
${ }^{30}$ As shown in Dreher et al. (2013b), donor's geopolitical motives for grantig aid reduce the effectiveness of aid in increasing economic growth.
} 
could also imply that the targeting of aid towards budget or project aid, while significant, is not yet sufficiently elaborated. To the extent that donors aim at increases in growth, a more careful allocation following the recommendations of our model should be able to improve outcomes with respect to growth. Future research might then want to investigate whether those parts of budget aid and project aid that are given in relation to informational advantages are indeed more effective in improving outcomes than those parts of such aid flows that are given due to other reasons. A differential analysis for different (groups) of bilateral and multilateral donors could also give additional insights as to which donors do and do not take account of information and bias, and whether these differences can explain potentially differential effects in the effectiveness of these donors' aid. Finally, other types of delivering aid might also be investigated with respect to whether or not they are allocated in light of information and preferences. ${ }^{31}$ We leave these questions for future research.

\footnotetext{
${ }^{31}$ As one example, our model could be used to explain the increasing amount of aid that is channeled via multilateral institutions as non-core aid ("multi-bi aid"), see Eichenauer and Hug (2013).
} 


\section{References}

[1] Alesina, Alberto and Allan Drazen, 1991, Why Are Stabilizations Delayed? American Economic Review 81: 1170-1188.

[2] Alesina, Alberto and David Dollar, 2000, Who gives foreign aid to whom and why? Journal of Economic Growth 5: 33-63.

[3] Ai, C. Chunrong and Edward C. Norton, 2003, Interaction Terms in Logit and Probit Models, Economics Letters 80, 1: 123-129.

[4] Bardhan, Pranab, 2002, Decentralization of Governance and Development, Journal of Economic Perspectives 16: 185-205.

[5] Berger, Daniel, William Easterly, Nathan Nunn and Shanker Satyanath, 2013, Commercial Imperialism? Political Influence and Trade during the Cold War, American Economic Review 103, 2: 863-896.

[6] Berger, Helge and Volker Nitsch, 2008, Zooming out: The trade effect of the euro in historical perspective, Journal of International Money and Finance 27, 8: 1244-1260.

[7] Berthèlemy, Jean-Claude, 2006, Bilateral Donors' Interest vs. Recipients' Development Motives in Aid Allocation: Do All Donors Behave the Same? Review of Development Economics 10, 2: 179-194.

[8] Berthèlemy, Jean-Claude and Ariane Tichit, 2004, Bilateral donors aid allocation decisions: a three-dimensional panel analysis, International Review of Economics and Finance 13, 3: 253-274.

[9] Besley, Timothy and Torsten Persson, 2011, Pillars of Prosperity: The Political Economics of Development Clusters, Princeton University Press.

[10] Bjørnskov, Christian and Niklas Potrafke, 2011, Politics and Privatization in Central and Eastern Europe: A Panel Data Analysis, Economics of Transition 19, 2: 201-230.

[11] Buis, Maarten L., 2010, Stata tip 87: Interpretation of interactions in non-linear models, The Stata Journal 10, 2: 305-308.

[12] Chauvet, Lisa, Paul Collier and Andreas Fuster, 2013, Supervision and Project Performance: A Principal-Agent Approach. Unpublished. 
[13] Claessens, Stijn, Danny Cassimon and Bjorn van Campenhout, 2009, Evidence on Changes in Aid Allocation Criteria, World Bank Economic Review 23, 2: 185-208.

[14] Clemens, Michael A., Steven Radelet, Rikhil R. Bhavnani and Samuel Bazzi, 2011, Counting Chickens when they Hatch: Timing and the Effects of Aid on Growth, Economic Journal 122, 561: 590-617.

[15] Cordella, Tito and Giovanni dell'Ariccia, 2007, Budget Support Versus Project Aid: A Theoretical Appraisal, Economic Journal 117: 1260-1279.

[16] Crawford, Vincent and Joel Sobel, 1982, Strategic Information Transmission, Econometrica 50: 1431-1451.

[17] Dessein, Wouter, 2002, Authority and Communication in Organizations, Review of Economic Studies 69: 811-838.

[18] Dietrich, Simone, 2010, Does donor selectivity in aid delivery help the poor? APSA 2010 Annual Meeting Paper. Available from: http://ssrn.com/abstract=1644727.

[19] Dollar, David and Victoria Levin, 2006, The increasing selectivity of foreign aid, 19842003, World Development 34, 12: 2034-2046.

[20] Drazen, Allan, 2002, Conditionality and Ownership in IMF Lending: A Political Economy approach, IMF Staff Papers 49: 36-67.

[21] Dreher, Axel, Kai Gehring, Christos Kotsogiannis and Silvia Marchesi, 2013a, Information transmission within federal fiscal architectures: Theory and evidence. Unpublished.

[22] Dreher, Axel, Vera Eichenauer and Kai Gehring, 2013b, Geopolitics, Aid and Growth. Unpublished.

[23] Dreher, Axel, Jan-Egbert Sturm and James R. Vreeland, 2009a, Development Aid and International Politics: Does membership on the UN Security Council influence World Bank decisions? Journal of Development Economics 88: 1-18.

[24] Dreher, Axel, Jan-Egbert Sturm and James R. Vreeland, 2009b, Global Horse Trading: IMF loans for votes in the United Nations Security Council. European Economic Review 53: $742-757$.

[25] Dreher, Axel, 2006, Does Globalization Affect Growth? Evidence from a new Index of Globalization, Applied Economics 38, 10: 1091-1110. 
[26] Easterly, William, 2006, The White Man's Burden: Why the West's Efforts to Aid the Rest Have Done So Much Ill and So Little Good. London: The Penguin Press.

[27] Easterly, William, 2008, Institutions: Top Down or Bottom Up? American Economic Review Papers and Proceedings 98: 95-99.

[28] Egger, Peter and Mario Larch, 2011, An assessment of the Europe agreements' effects on bilateral trade, GDP, and welfare, European Economic Review 55, 2: 263-279.

[29] Eichenauer, Vera Z. and Simon Hug, 2013, The politics of special purpose trust funds. Unpublished.

[30] Faye, Michael and Paul Niehaus, 2012, Political Aid Cycles, American Economic Review 102, 7: 3516-3530.

[31] Fernandez, Raquel and Dani Rodrik, 1991, Resistance to Reform: Status Quo Bias in the Presence of Individual-Specific Uncertainty, American Economic Review 81: 11461155.

[32] Gassebner, Martin, Noel Gaston and Michael Lamla, 2011, The Inverse Domino Effect: Are Economic Reforms Contagious? International Economic Review 52, 1: 183-200.

[33] Greene, William H., 2011, Econometric Analysis, Prentice Hall, Seventh Edition.

[34] Greene, William H., 2010, Testing Hypotheses about Interaction Terms in Nonlinear Models, Economics Letters 107: 291-96.

[35] Hagen, Rune Jansen, 2011, Dancing the H-Street Waltz? Policy Choice in AidDependent Countries, University of Bergen Working Papers No 16/08.

[36] Harris, Milton and Arthur Raviv, 2005, Allocation of Decision Making Authority, Review of Finance 9: 353-383.

[37] Harris, Milton and Arthur Raviv, 2008, A theory of Board Control and Size, Review of Financial Studies 21: 1797-1832.

[38] Hefeker, Carsten, 2006, Project aid or budget aid? The interest of governments and financial institutions, Review of Development Economics 10: 241-252.

[39] Hoeffler, Anke and Verity Outram, 2011, Need, Merit, or Self-Interest: What Determines the Allocation of Aid? Review of Development Economics 15, 2: 237-250. 
[40] Hollyer, James R., B. Peter Rosendorff and James Raymond Vreeland, 2011, Democracy and Transparency. Journal of Politics 73: 1194-1205.

[41] International Monetary Fund, 2001, Strengthening country ownership of Fundsupported programs, Washington, DC.

[42] Khan, Mohsin S. and Sunil Sharma, 2001, IMF Conditionality and Country Ownership of Programs, IMF Working Paper 142, Washington, DC: International Monetary Fund.

[43] Koeberle, Stefan G., 2004, Conditionality: under what conditions? In S. Koeberle, H. Bedoya, P. Silarszky and G. Verheyen (Eds.), Conditionality revisited, Washington, World Bank: 57-84.

[44] Koeberle, Stefan G. and Zoran Stavreski, 2006, Budget support: Concept and issues. Budget support as more effective aid? Recent experiences and emerging lessons. In S. Koeberle, H. Bedoya, P. Silarszky and G. Verheyen (Eds.), Conditionality revisited, Washington, World Bank: 3-23.

[45] Kuziemko, Ilyana, and Eric Werker, 2006, How much is a Seat on the Security Council Worth? Foreign Aid and Bribery at the United Nations, Journal of Political Economy 114: $905-930$.

[46] Lessmann, Christian and Gunther Markwardt, 2010, Decentralization and Foreign Aid Effectiveness: Do Aid Modality and Federal Design Matter in Poverty Alleviation? CESifo Working Paper No. 3025.

[47] Mallaby, Sebastian, 2004, The World's Banker: A Story of Failed States, Financial Crises, and the Wealth and Poverty of Nations, Council on Foreign Relations Books, Penguin Press.

[48] Marchesi, Silvia, Laura Sabani and Axel Dreher, 2011, Read my lips: the role of information transmission in multilateral reform design, Journal of International Economics 84: 86-98.

[49] Marshall, Monty G. and Keith Jaggers, 2009, Polity IV Project: Political Regime Characteristics and Transitions, 1800-2007, University of Maryland.

[50] Nordtveit, Ingvild, 2012, Herd behavior or increased efficiency: What determines the allocation of general budget support? University of Bergen. Unpublished.

[51] OECD, 2012, Creditor Reporting System, http://stats.oecd.org/Index.aspx?datasetcode=CRS1 (Accessed on 15.3.2012). 
[52] OECD, 2005, 2008, The Paris Declaration on Aid Effectiveness and the Accra Agenda for Action. Available from: www.oecd.org/dataoecd/11/41/34428351.pdf.

[53] Outtara, Bazoumana and Eric Strobl, 2008, Aid, policy and growth: Does aid modality matter? Review of World Economics 144: 347-365.

[54] Potrafke, Niklas, 2011, Intelligence and Corruption, Economics Letters 114, 1:109-112.

[55] PRS Group, 1998, International Country Risk Guide (ICRG), Syracuse, NY: IBC. http://www.prsgroup.com.

[56] Rajan, Raghuram, 2008, The future of the IMF and the World Bank, American Economic Review Papers and Proceedings 98: 110-115.

[57] Santos Silva, Joao and Silvana Tenreyro, 2006, The Log of Gravity, Review of Economics and Statistics 88, 4: 641-658.

[58] Sigelman, Lee and Langche Zeng, 1999, Analyzing Censored and Sample-Selected Data with Tobit and Heckit Models, Political Analysis 8, 2: 167-182.

[59] Strezhnev, Anton and Erik Voeten, 2013, United Nations General Assembly Voting Data, http://hdl.handle.net/1902.1/12379 UNF:5:NpHV5DXWPNWMWOrLGTjQYA== Erik Voeten [Distributor] V5 [Version].

[60] Tabellini, Guido and Alberto Alesina, 1990, Voting on the budget deficit, American Economic Review 80: 37-49.

[61] Van de Sijpe, Nicolas, 2013, Is Foreign Aid Fungible? Evidence from the Education and Health Sectors, Policy Research Working Paper 6346, World Bank, Washington DC.

[62] World Bank, 2013, World Development Indicators, CD-Rom. Washington, D.C. http://data.worldbank.org/data-catalog/world-d (Accessed on 4.09.2013).

\section{Appendices}

\section{Appendix A: Definition and properties of the communication game}

This Appendix provides the definition of the communication game and the properties of the equilibrium outlined in Section 3.

Let $t \in[0, D]$ denote the message that the donor sends to the recipient, when asked to offer its advice. Let $q(t \mid d)$ denote the density function that the donor sends message $t$ when it 
has observed $d . q(t \mid d)$ is the reporting rule chosen by the donor. Let $p(g, t)$ be the action rule (i.e., the policy) chosen by the recipient, given the donor has sent message $t$ to the recipient. We then have that:

Definition 1 A Perfect Bayesian Nash Equilibrium of the communication game consists of a reporting rule $q(t \mid d)$ and an action rule for the recipient $p(g, t)$ such that

i) for each $d \in[0, D], \int_{R} q(t \mid d) d t=1$. If $t^{*}$ is in the support of $q(t \mid d)$, $t^{*}$ is such that

$$
t^{*}=\arg \min L^{D}=\int_{0}^{G}\left[p(g, t)-p_{D}^{*}\right]^{2} f_{G}(g) d g,
$$

and

ii) for each $t, p(g, t)$ solves

$$
p(g, t)=\arg \min L^{G}=\int_{0}^{G}\left[p(g, t)-p_{G}^{*}\right]^{2} g(d \mid t) d d,
$$

where $g(d \mid t)=\frac{q(t \mid d) f_{D}(d)}{\int_{0}^{D} q(t \mid \theta) f_{D}(\theta) d \theta}$.

According to condition $(i)$, the reporting rule $q(t \mid d)$ chosen by the donor minimizes the donor's expected loss, given the recipient's action rule $p(g, t)$. In other words, the equilibrium reporting rule $q(t \mid d)$ induces the recipient to choose policies $p(g, t)$, which minimize the expected loss of the donor. Condition ( $i i$ ) simply says that the recipient responds optimally to each donor report $t$. Namely, the recipient uses Bayes' rule to update its prior on $d$, given the donor's reporting strategy and the signal received. Then, given the donor's report $t$ and the posterior density function of $d$ given $t$ - that is, $g(d \mid t)-p(g, t)$ minimizes the recipient's expected loss. Crawford and Sobel (1982) show that this communication game does not have a full revelation equilibrium, but that there are multiple equilibria which are all partition equilibria. More specifically, the state space $[0, D]$ is partitioned into intervals and the donor only reveals which interval the true value of $d$ belongs to. The following characterizes the relevant equilibria of the communication game.

Proposition 1 There exists at least one equilibrium with the following properties: there is a positive integer $N$, such that one can define a set of $N+1$ real numbers, with generic element denoted by $d_{i}$, such that $0=d_{0}<d_{1}<\ldots<d_{N-1}<d_{N}=1$, and

(a) $q(t \mid d)$ is uniform, supported on $\left[d_{i}, d_{i+1}\right]$, if $t \in\left(d_{i}, d_{i+1}\right)$;

(b) $p(g, t)=g+\frac{d_{i}+d_{i+1}}{2}-b$, for all $t \in\left(d_{i}, d_{i+1}\right)$.

\section{Moreover}

(i) $\int_{0}^{G}\left[g+\left(\frac{d_{i}+d_{i+1}}{2}\right)-\left(g+d_{i}\right)-B\right]^{2} f(g) d g=\int_{0}^{G}\left[\left(g+d_{i}\right)-\left[g+\left(\frac{d_{i-1}+d_{i}}{2}\right)\right]+B\right]^{2} f(g) d g$;

(ii) $d_{0}=0 ; d_{N}=D$. 
Proof: The proof follows directly from Theorem 1 in Crawford and Sobel (1982).

Condition $(i)$ is an 'arbitrage' condition which says that for states of nature that fall on the boundaries of two intervals the donor must be indifferent between the actions $(p(g, t))$ on these two intervals. Condition $(i)$ defines a second order linear differential equation on $d_{i}$, while condition (ii) specifies its initial and terminal conditions. Since the donor is not informed on the true value of $g$, when choosing $t$, it will take the expected value of $g$, that is $G / 2$. The arbitrage condition $(i)$ then, for $i=1, \ldots, N-1$,reduces to

$$
\frac{G}{2}+\left(\frac{d_{i+1}+d_{i}}{2}\right)-\left(\frac{G}{2}+d_{i}\right)-B=\frac{G}{2}+d_{i}-\left[\frac{G}{2}+\left(\frac{d_{i-1}+d_{i}}{2}\right)\right]+B,
$$

from which it implies

$$
d_{i+1}=2 d_{i}-d_{i-1}+4 B .
$$

This second order linear difference equation has a class of solutions parameterized by $d_{1}$ (given that $d_{0}=0$ )

$$
d_{i}=i d_{1}+2 i(i-1) B, \quad i=1, \ldots, N-1 .
$$

Given that $d_{N}=D$ it is the case that

$$
d_{1}=\frac{D-2 N(N-1) B}{N},
$$

which, using (A.4) and substituting for the value of $d_{1}$, becomes

$$
d_{i}=\frac{i D}{N}-2 i(N-i) B, \quad i=1, \ldots, N .
$$

From (A.7) it follows that

$$
d_{i}-d_{i-1}=\frac{D}{N}+2(2 i-N-1) B,
$$

where the width of the interval increases by $4 B$ for each increase in $i$.

Notice that the centralization game is entirely symmetric to the delegation game. As before, the recipient's report $r$ is determined by a partition $\left\{g_{i}\right\}$ of $[0, G]$. Again, it is possible to define a reporting rule $q(r \mid g)$ and a posterior belief

$$
g(g \mid r)=\frac{q(r \mid g) f_{g}(g)}{\int_{0}^{G} q(r \mid \eta) f_{G}(\eta) d(\eta)}
$$

such that, given the report $r \in\left[g_{i}, g_{i+1}\right]$, the donor's expected value of $g$ is $\left(g_{i}+g_{i+1}\right) / 2$ (posterior mean of the random variable $\widetilde{g}$, given $r$ ). Thus, the donor will implement the following policy

$$
p(g, r)=\frac{g_{i}+g_{i+1}}{2}+d+e \quad \text { if } \quad r \in\left[g_{i}, g_{i+1}\right], \quad i=1, \ldots, N-1 .
$$


The partition $\left\{g_{i}\right\}$ of $[0, G]$ is computed using the conditions $(i)$ and $(i i)$ in Proposition 1 , in a similar way as above, that is

$$
g_{N-i}-g_{N-(i-1)}=\frac{G}{N}-2(2 i-N-1) B
$$

where the width of the interval decreases by $4 B$ for each increase in $i$.

\section{Appendix B: Derivation of equations (6) and (8)}

Under delegation, following Proposition 1 and using (A.8), the donor's ex ante expected loss for the equilibrium of size $N$ is given by

$$
\begin{aligned}
L_{D}^{D}(N, B, D) & =\int_{0}^{D}\left(p(g, t)-p_{D}^{*}\right)^{2} g(d \mid t) d d \\
& =\int_{0}^{D}\left(g+\frac{d_{i}+d_{i+1}}{2}-b-g-d-e\right)^{2} g(d \mid t) d d \\
& =\frac{1}{D} \sum_{i=1}^{N} \int_{d_{i-1}}^{d_{i}}\left(\frac{d_{i-1}+d_{i}}{2}-d-B\right)^{2} d d \\
& =\frac{1}{D} \frac{1}{12} \sum_{i=1}^{N}\left(d_{i}-d_{i-1}\right)^{3}+\frac{1}{D} B^{2}\left(d_{0}-d_{N}\right), \\
& =\frac{1}{12} \sum_{i=1}^{N}\left[\frac{D}{N}+2(2 i-N-1) B\right]^{3}+\frac{1}{D} B^{2}\left(d_{0}-d_{N}\right), \\
& =\sigma_{D}^{2}+B^{2}\left(d_{0}=0 ; d_{N}=C, \text { see Proposition } 1\right),
\end{aligned}
$$

with the last equality following from equation (7). Here, $D$ stands for delegation and $\sigma_{D}^{2}$ is the ex-ante residual variance of $d$, that is the uncertainty about $d$ faced by the recipient before being reported by the donor the equilibrium signal $t$.

Under centralization, following Proposition 1 and using (A.11), the donor's ex ante expected 
loss for the equilibrium of size $N$ is given by:

$$
\begin{aligned}
L_{C}^{D}(N, B, D) & =\int_{0}^{G}\left[p(d, r)-p_{D}^{*}\right]^{2} g(g \mid r) d g \\
& =\frac{1}{G} \sum_{i=1}^{N} \int_{g_{i}-1}^{g_{i}}\left(\frac{g_{i}+g_{i+1}}{2}+d+e-d-g-e\right)^{2} d d \\
& =\frac{1}{G} \sum_{i=1}^{N} \int_{g_{i}-1}^{g_{i}}\left(\frac{g_{i-1}+g_{i}}{2}-g\right)^{2} d d \\
& =\frac{1}{G} \frac{1}{12} \sum_{i=1}^{N}\left(g_{i}-g_{i-1}\right)^{3} \\
& =\frac{1}{G} \frac{1}{12} \sum_{i=1}^{N}\left[\frac{G}{N}+2(2 i-N-1) B\right]^{3} \\
& =\sigma_{g}^{2}
\end{aligned}
$$

where the last equality follows from equation (9). 


\section{Appendix C: Proof of statements in Section 3}

The statement given in Section 3 follows directly from Proposition 2 below. By comparing its ex ante expected loss under delegation $\left(L_{D}^{D}(N, B, D)\right)$ with the one it incurs under centralization $\left(L_{C}^{D}(N, B, D)\right)$, the donor determines whether or not to retain its control rights over policies.

Proposition 2 The donor prefers delegation if and only if $G \geq D(G, B)$, where $D(G, B)$ is continuous and increasing in $G$ and, for any $B, D(G, B)<G$.

Proof: The proof follows Theorem 1 in Harris and Raviv (2005). 
Appendix D: Sources and Definitions

\begin{tabular}{llll}
\hline \hline & Variable & Definition & Source \\
\hline DEPENDENT & Project Aid & Log of aid committed in constant & OECD (2012) \\
VARIABLES & & 2009 million US dollars & \\
& Budget Aid & Log of aid committed in constant & OECD (2012) \\
& & 2009 million US dollars
\end{tabular}

CONTROL VARIABLES
$(\log )$ GDP
Log of GDP p.c.,
World Bank (2013)
constant 2000 US\$
CPIA
World Bank's Country Policy and Institutional Assessment
(log) Population Log of population
CPIA, World Bank
Voting with USA The share of votes in a year that a country votes in line with the
World Bank (2013)
Strezhnev and Voeten United States in the United Nations General Assembly
Trade with USA Sum of exports and imports with (2013) the United States (in constant 2005
UN Comtrade (2012) 1000 US\$)

\section{VARIABLES OF INTEREST}

\section{Bias}

$\begin{array}{ll}\begin{array}{l}\text { Government } \\ \text { Stability }\end{array} & \begin{array}{l}\text { Measures the government's } \\ \text { capability in carrying out } \\ \text { its declared programs/policies and } \\ \text { its ability to stay in office } \\ \text { Ethnic Tensions } \\ \text { Measures the degree of tension } \\ \text { within a country which can be } \\ \text { attributable to racial, cultural and } \\ \text { language division }\end{array} \\ \text { Bureaucratic } & \begin{array}{l}\text { Measures the bureaucracy's } \\ \text { strength and expertise to govern, }\end{array} \\ \text { Quality } & \begin{array}{l}\text { without the necessity for drastic } \\ \text { changes in policy or interruptions } \\ \text { in government services }\end{array} \\ \text { KOF Index of Globalization, } \\ \text { Globalization } & \begin{array}{l}\text { ranging between 1-100 with higher } \\ \text { values showing more globalization }\end{array}\end{array}$

ICRG (2013)

ICRG (2013)

ICRG (2013)

Dreher (2006)

\section{Knowledge}

Transparency

Share in all data series for which

World Bank (2013) data are reported 
Appendix E: Descriptive Statistics (estimation sample of Table 1, column 3)

Variable

Project Aid

Budget Aid

(log) GDP per capita

CPIA

(log) Population

Voting with USA

Trade with USA

Government Stability

Ethnic Tensions

Bureaucratic Quality

Globalization Index

Transparency

\begin{tabular}{|rrrrr|}
\hline \multicolumn{1}{|c}{ N } & \multicolumn{1}{c}{ Sean } & Min & \multicolumn{1}{c|}{ Max } \\
\hline 1059 & 358.62 & 375 & 0 & 2513.05 \\
1059 & 34.15 & 103.39 & 0 & 1267.15 \\
1059 & 6.92 & 1.03 & 3.91 & 8.94 \\
1059 & 3.31 & 0.64 & 1 & 5.5 \\
1059 & 16.56 & 1.44 & 13.5 & 20.99 \\
1059 & 0.3 & 0.1 & 0.1 & 0.63 \\
1059 & 13.51 & 2.3 & 6.83 & 19.51 \\
1059 & 8.48 & 1.82 & 2.75 & 12 \\
1059 & 3.79 & 1.35 & 0 & 6 \\
1059 & 1.6 & 0.81 & 0 & 3.5 \\
1059 & 47.1 & 10.46 & 22.3 & 76.79 \\
1059 & 0.67 & 0.09 & 0.32 & 0.87 \\
\hline
\end{tabular}


Appendix F: Correlations (estimation sample of Table 1, column 3)

\begin{tabular}{|c|c|c|c|c|c|c|c|c|c|c|c|}
\hline & Project Aid & Budget Aid & $\begin{array}{l}(\log ) \text { GDP } \\
\text { per capita }\end{array}$ & CPIA & $\begin{array}{c}(\log ) \\
\text { Population }\end{array}$ & $\begin{array}{c}\text { Voting with } \\
\text { USA }\end{array}$ & $\begin{array}{c}\text { Trade with } \\
\text { USA }\end{array}$ & $\begin{array}{l}\text { Government } \\
\text { Stability }\end{array}$ & $\begin{array}{c}\text { Ethnic } \\
\text { Tensions }\end{array}$ & $\begin{array}{c}\text { Bureaucratic } \\
\text { Quality }\end{array}$ & $\begin{array}{l}\text { Globalization } \\
\text { Index }\end{array}$ \\
\hline Project Aid & 1 & & & & & & & & & & \\
\hline Budget Aid & 0.2487 & 1 & & & & & & & & & \\
\hline (log) GDP per capita & -0.2935 & -0.2167 & 1 & & & & & & & & \\
\hline CPIA & 0.1798 & 0.1021 & 0.3868 & 1 & & & & & & & \\
\hline (log) Population & 0.54 & 0.0643 & -0.0532 & 0.151 & 1 & & & & & & \\
\hline Voting with USA & -0.3665 & -0.1421 & 0.0374 & -0.218 & -0.2196 & 1 & & & & & \\
\hline Trade with USA & 0.1227 & -0.1706 & 0.5931 & 0.2989 & 0.5709 & -0.1022 & 1 & & & & \\
\hline Government Stability & 0.0958 & 0.0927 & 0.073 & 0.2619 & 0.0547 & -0.2394 & 0.0316 & 1 & & & \\
\hline Ethnic Tensions & -0.1935 & -0.0179 & 0.3819 & 0.3276 & -0.1725 & 0.1369 & $0.149 \varsigma$ & 0.0678 & 1 & & \\
\hline Bureaucratic Quality & -0.0037 & -0.0965 & 0.4529 & 0.3993 & 0.2132 & -0.0191 & 0.4497 & -0.016 & 0.1783 & 1 & \\
\hline Globalization Index & -0.0507 & -0.0898 & 0.7467 & 0.5366 & 0.0114 & -0.1835 & 0.5363 & 0.1599 & 0.3242 & 0.4606 & 1 \\
\hline Transparency & 0.2724 & 0.042 & 0.4564 & 0.5871 & 0.3256 & -0.3267 & 0.4474 & 0.1932 & 0.1851 & 0.3112 & 0.5869 \\
\hline
\end{tabular}

